This is an electronic reprint of the original article. This reprint may differ from the original in pagination and typographic detail.

Author(s): Taipale, Sakari

Title: $\quad$ Mobilities in Finland's Information Society Strategies from 1995 to 2010

Year: $\quad 2013$

Version:

Please cite the original version:

Taipale, S. (2013). Mobilities in Finland's Information Society Strategies from 1995 to 2010. Mobilities, 8(2), 293-311. https://doi.org/10.1080/17450101.2012.655975

All material supplied via JYX is protected by copyright and other intellectual property rights, and duplication or sale of all or part of any of the repository collections is not permitted, except that material may be duplicated by you for your research use or educational purposes in electronic or print form. You must obtain permission for any other use. Electronic or print copies may not be offered, whether for sale or otherwise to anyone who is not an authorised user. 


\title{
MOBILITIES IN FINLAND'S INFORMATION SOCIETY STRATEGIES \\ FROM 1995 TO 2010
}

\author{
Sakari Taipale
}

Corresponding author

Dr Sakari Taipale

Postdoctoral Research Fellow

Department of Social Sciences and Philosophy

University of Jyväskylä, Finland

Postal address

P.O. Box 35, 40010 University of Jyväskylä, Finland

Tel. +358400728852 Fax +358142603101

E-mail sakari.taipale@jyu.fi

Running head: Mobilities in Finland 


\begin{abstract}
The article explores how Finland has taken into account challenges related to new forms of mobility in its national information society strategies. The study is based on the 'mobilities paradigm' and analyses the national strategies published from the mid-1990s to 2010. Besides theoretical and methodological results, the article identifies two trends from the data; a further intermingling of physical movement of objects and virtual mobility and a tendency to reduce corporeal mobility. Communicative and imaginative forms of mobility remain largely overlooked in the strategies. Finally, the results imply that a genuinely mobile information society has still to arrive in Finland.
\end{abstract}

\title{
KEYWORDS
}

Information society, mobilities, mobility paradigm, policy, strategy, Finland 


\section{INTRODUCTION}

Finland acquired an international reputation as a leading information society in the 1990s. With the success of Nokia mobile phones global media proclaimed Finland as a forerunner of the information age (Klee and Bensk, 1999; Silberman, 1999) in terms of mobile phone penetration rates, internet hosts and web connections. This 'Finnish miracle', as it was called by Paija (2001) and Benner (2003, 135), received a lot of international attention and was widely thought to hold the key to success in the information age (Castells and Himanen, 2002). Usually such success was associated with the combination of the Nordic welfare state model, that provides a highly-skilled labour force by means of a free education system, and a dedicated research and innovation policy (Benner, 2003, 136).

Inspired by Nokia’s success in mobile telecommunications, scholars started to talk about the birth of a mobile information society (Kopomaa, 2000; Puro, 2002; Oksman, 2006). The Finnish scholar Timo Kopomaa (2000) argued that the mobile phone played a central role in the shaping of the Finnish information society which could be understood as one where people's ways of life were based on either complete mobility or the lack of it (Kopomaa, 2000, 11). Generally, the mobile phone was seen as a herald of the Finnish mobile information society, where people live nomadic lives with the possibility of contacting the whole world from anywhere and anytime. Although other portable information and communication technologies (ICTs), such as laptops, mobile internet connections and iPods, were popularized only a few years later, their role in the creation of a genuinely mobile information society was not foreseen at the time. Additionally, the other forms of 
mobility, such as increased intra-European movement of workers or virtual travelling in online communities, were not forecast to have such a role in the creation of the mobile information society as they have today. It is only now, when a number of new mobile technologies have emerged, that the physical movements of people and objects are setting new challenges for society (e.g. work-related immigration, a new wave of beggars, a growing volume of online shopping) (e.g. Peters, 2006; Sheller and Urry, 2006; Urry, 2007; Pellegrino, 2011; Taipale, forthcoming), and we understand the limited role of Finland's mobile communication business in the creation of a truly mobile information society.

It is against this backdrop that the article analyses Finland's information society policies to see whether they respond to those challenges articulated within the so-called 'mobility paradigm'. The article investigates how Finland has taken into account various challenges related to new forms of mobility in its national information society strategies over the last 15 years. In this manner, the article also searches for a further explanation of why the country has lost its position as a leading information society. The empirical part of the study covers the period from the mid-1990s to 2010, the time when national information society strategies were framed.

Theoretically, the paper is premised on the mobilities paradigm. This paradigm was largely formulated by John Urry $(2007,19)$, who argues that sociologists have neglected the role of mobility and communications in the contemporary globalized world. The increased mobility overall brings with it a loosening of the fixed structures of the industrial society (Peters, 2006; Sheller and Urry, 2006; Urry, 2007). It is also apparent that this new ‘movement-driven’ epoch gains support from the critics of methodological nationalism, 
which questions the long-prevailing assumption that society and nation-states are natural forms of the modern world (Wimmer and Glick Schiller, 2002; Beck, 2006, 24). As the continuous updating of national (and supra-national) information society strategies shows, however, nation-states have not completely lost their significance in the era of new mobilities. Nation-states together with supranational alliances (such as the EU) are still the only functional bodies that are able to govern the social and mobility-related problems of our time at least in to some degree. It is considered here that the mobility paradigm also provides a distinct conceptual framework for studying national information society strategies and identifying weaknesses related to their national outlooks. A certain typology of mobility types presented within the paradigm is applied here to analyse strategy documents. In other words, the analytic strategy of the paper is in line with theory-directed content analysis (Hsieh and Shannon, 2005).

The article is motivated both by a practical interest in better understanding the recent development of the Finnish information society and by the ambition to put the mobility typology presented by John Urry to the test. Even if the mobility paradigm has given birth to a completely new field of sociology, attempts to study systematically the correspondence between its main concepts and empirical phenomena have been rare. It is also of current international interest to understand how 'mobilities' are articulated in information society strategies. Mobility (and the reduction of 'unnecessary' mobility) is one of the key factors for achieving an internationally competitive and sustainable information society (Banister et al., 2000, 32; Banister, 2008) but the aspects of mobility actually being considered in the strategic development of societies, and the kinds of challenges the intermingling of different mobilities (e.g. bodily, imaginative, communicative) creates for information 
societies should be studied much more carefully. This article contributes to this particular need and Finland serves as an example owing to its early success in ICT development and its more recent difficulty in maintaining its position.

\section{PREVIOUS LITERATURE}

\subsection{The mobilities paradigm}

The basis of the mobilities paradigm was comprehensively formulated in John Urry's book Sociology Beyond Societies: Mobilities for the Twenty-First Century (2000a). In this seminal study Urry frames how societal structuring and transformation have been bound up with an idea of what it is to be a member of a given nation-state with certain social rights and duties. Instead of this rigidity, Urry (2000a, 2) suggests that an increasing variety of mobilities undermines societal borders and their permanence. Mobilities are transforming the historical subject matter of sociology, that is, an individual 'western' society with its endogenous social characteristics (Urry, 2000b). Therefore, he suggests a new paradigmatic approach wherein the social sphere of life would treat 'social' not as 'societal' but as 'mobile'. This paradigmatic change is alternatively referred to by the term 'mobile turn' (Urry, 2003, 171).

It is a characteristic of this new 'movement-driven' sociology that we should not stick to a prejudiced view of mobility as twentieth-century sociology did by exploring educational, income, occupational and social mobility as well as social movements. Instead, attention 
should be paid to a greater variety of mobilities, such as mobility of people, information, capital, ideas, sounds and entire cultures, and the ways in which they interact and constitute hybrid mobilities (Urry, 2000a, 2007). Other scholars have analysed the distinction between social mobility studies and 'new mobility studies' just to show how challenging it is to combine these two approaches (Kaufmann and Montulet, 2008). The term 'social mobility' is a metaphor of movement, whereas the mobilities paradigm deals with physical and immaterial movement. Some critical remarks have also been made. Tim Cresswell (2010, 18-19), for example, emphasizes the significance of 'moorings' along with mobility, and argues that mobility is not one but rather an entanglement of physical movements, representations, and practices. Cresswell $(2010,18)$ agrees, however, that the bringing together of diverse modes of movement in a sort of typology, ranging from bodily and physical to imaginative and virtual modes of movements, is something novel in the social sciences.

The mobility typology in question is presented in various publications (Urry, 2007, 47; Larsen, Urry and Axhausen 2006, 47-48; Büscher and Urry, 2009, 101-102). The typology consists of five modes of mobility. Corporeal mobility (or travelling) is typically defined first as it refers to the movement of people in terms of their work, family and leisure time, but it may also refer to various forms of human migration. The other mode of mobility is the physical movement of objects, which covers both commercial and non-commercial exchange of physical items between producers, consumers/ordinary people and retailers. Imaginative mobility takes place through images that are effected through media such as radio and television. In contrast to imaginative movement, virtual mobility makes a stronger reference to such movement as takes place in real time, typically on the Internet, 
and transcends social and geographical distances. Communicative mobility alludes to person-to-person communication by means of postcards, faxes, telephones, emails and the like. Some earlier versions of this typology do not explicitly separate communicative mobility from other forms of movement (e.g. Urry, 2000a, 2002). Nevertheless, these five mobility types are in many ways interdependent categories (Larsen, Urry and Axhausen 2006, 47) as one type of movement can intermingle with the other.

It is appropriate to note at this point that John Urry and other mobility scholars often talk about 'travelling' instead of mobility. In relation to tourism and transportation practices (Peters, 2006; Sheller and Urry, 2004; Urry, 2007) the term 'travelling' works rather well but in the context of virtual and communicative mobilities its applicability is somewhat tenuous. Furthermore, travelling refers to goal-oriented journeys made by individuals or groups of people, which could be confusing in this connection as the studied national information society strategies set goals at the country level. Hence, only the concept of mobility is treated in this study.

The application of the presented mobility typology to a systematic empirical study contains some real challenges. First and foremost, owing to the interdependence of different mobility forms, typology is not unambiguous in its description of how to classify various forms of movement in the five categories. For instance, it may be asked whether the use of Internet Protocol Television (IPTV), through which images of places and people are transferred, but which may be viewed in real-time and discussed with other people simultaneously, should be categorized as imaginative or virtual movement. Second, the mobility paradigm in general is based on the notions of complexity (e.g. hybrid systems, 
hyper-complexity; Urry, 2007, 26-31), which can be seen as an attempt to distant it from the most simplifying research strategies (statistical ones in particular) (Büscher and Urry, 2009). At the same time, it is clear that the conceptual typology has been developed to be empirically tested. To promote the practical applications of the mobility paradigm, leading scholars have outlined some guidelines for mobile methodology to show how mobilities enable new forms of sociological inquiry and explanation (Urry, 2007, 39-43; Büscher and Urry, 2009; Büscher, Urry and Witchger, 2010).

The mobility paradigm suggests that mobilities are constituted of various social, political and economic relations, and that the parallel examination of various mobilities may reveal how discourses prioritize one mode of mobility over another, and hence rather simplify than explain such relations (Büscher and Urry, 2009, 102). Inspired by this, the article at hand explores the appearance of various mobility types in strategy documents in order to reveal what modes of movement are considered to have the most significance for the development of the Finnish information society, and in contrast, what modes of movement are overlooked or completely ignored in the documents.

Whereas a large number of mobility studies (see a review by Büscher and Urry, 2009, 102108) have explored mobilities at the individual or community levels, and then generated policy recommendations from the results, this study adopts a different angle of approach. By examining the 'policies of mobility' framed in strategy documents, the article clarifies how different modes of mobility are fostered and/or ignored in the strategic development of the Finnish information society. In prior studies, policy recommendations have been mainly targeted at transport (Larsen, Urry and Axhausen, 2006, 124-132) and employment policy, 
as well as at the policies of ageing (Blossfeld, Buchholz and Hofäcker, 2009). Some inquiries have also paid heed to such social policy issues as social exclusion understood as

a distinction between ‘mobility rich’ and ‘mobility poor’ people (Ohnmacht, Maksim and Bergman, 2009).

\subsection{The Finnish information society}

The information society is a much exploited and debated concept used to describe the society in which we live today (e.g. Castells, 2000; Webster, 2002). Prior definitions variously emphasize the role of creation, dissemination, and utilization of information in different economic, political, cultural and organizational settings. Yet in this study the information society is viewed from the perspective of mobility and policy.

The article is premised on the idea that the information society is steered through political strategies which aim to create conditions for diverse forms of mobility (see also Inkinen, 2008). Instead of governing only the 'social' or economy, societies aim to manage mobilities by launching their information society strategies.

A brief introduction to the recent development of the Finnish information society is given from a comparative perspective before presentation of the data, methods and empirical analysis. Some indicators of information society development are explored to show Finland's position in a wider international context and how the position has changed within the last few years. As foreshadowed above, the early years of the Finnish information society have been described as a miracle (Paija, 2001; Benner, 2003). Finland was 
considered as an international forerunner in terms of mobile phone penetration, internet subscriptions and the utilization of ICT-based innovations at the turn of the new millennium (Castells and Himanen, 2002; Turkki, 2009, 13). More recent statistics, however, show that Finland's position has changed when compared with other advanced information societies. Finland still ranks among the top 10 or 20 countries depending on the indicator applied, but its reputation as a forerunner is gone.

The International Telecommunication Union (ITU) is a leading institution which measures and analyses information society development. From its previous aggregate measures the ICT Opportunity Index (ICT-OI) and Digital Opportunity Index (DOI), ITU has developed a single ICT Development Index (IDI), which measures ICT use, skills, and access through its three sub-indexes. The access and use sub-indexes have an equal weight of 40 per cent each, whereas the skills sub-index has a weight of 20 per cent (ITU 2009, 17).

The overall IDI index shows that Finland lost four rankings between 2002 and 2008 in a worldwide comparison. In 2002, Finland was in place 8 but in 2008 it ranked 12. The subindex for skill level reports that Finland is still doing excellently in terms of ICT skilfulness. In 2008, Finland was placed second, after the Korean Republic, when skills were measured by adult literacy rates and enrolments in secondary and tertiary education. The ICT use sub-index shows no change in ranking when 2002 and 2008 are compared; Finland held place 11 whereas such Eastern economies as Korea, Japan, and Singapore, and the Nordic countries Sweden and Denmark and Norway, ranked higher in this index. The ICT access sub-index shows a greater drop for Finland from place 14 to place 20 between 2002 and 2008. This decline is partially explained by a decrease in fixed telephone line 
penetration. Another reason is that some of the other top countries have improved their mobile broadband penetration rates faster than Finland. The sub-index for ICT access also includes indicators for Internet bandwidth per Internet user, the proportion of households with computers and the proportion of households with Internet access (ITU, 2008, 2009).

The digital economy ranking list (previously known as e-readiness ranking), which is a joint effort of the Economist Intelligence Unit and the IBM Institute for Business Value, provides another picture of Finland's recent development. This index consists of six categories which are indicative of connectivity and technology infrastructures, business environment, social and cultural environment, legal environment, government policy and vision, and consumer and business adoption. Both qualitative and quantitative criteria have been applied in the assessment. According to this ranking list, Finland has actually improved its overall standing, being in place 4 (out of 70 of the world's largest economies) in 2010, and Sweden held first place, followed by Denmark and the United States. A year earlier, in 2009, Finland was ranked only tenth, which may also be indicative of the index’s lack of robustness, but what is of particular interest to this study is Finland's poor performance in the 'Government Policy and Vision' comparison. Out of 70 of the world's top economies, there were 18 countries that scored higher than Finland. The United States and South Korea were in the lead, but also other Nordic countries, and many Southern Asian and Middle European countries were ahead of Finland (Economist Intelligence Unit, 2010).

'Government Policy and Vision' comparisons take into account, for example, how a government applies technology to operate and provide public services, how well citizens 
can interact with and receive more information from the government regardless of their own access to ICTs, and public spend on ICT as a proportion of GPD (Economist Intelligence Unit, 2010, 20). Finland's relatively low performance in this comparison is in line with previous criticism dealing with slow, disorganized and decentralized ICT development of the public sector (National Audit Office of Finland, 2008; Turkki, 2009). Actually, this seems to be one of the main reasons for Finland's stagnant information society development during the last few years.

In the light of this review and prior studies (Turkki, 2009, 19; Roivas, 2009) it can be concluded that Finland is still performing relatively well internationally. Countries that previously ranked behind Finland, however, have improved their performance faster than Finland. On the other hand, although Finland particularly needs to improve its egovernance policies and the implementation of related measures, the basic preconditions for a successful future as regards connectivity to ICTs and citizens’ education are good. The following analysis sheds more light on the factual contents of Finland's information society policies.

\section{DATA AND METHODS}

The research data of this study consist of four national information society strategies published between 1995 and 2010. ${ }^{1}$ The first of them, Finland's Way to the Information Society: The National Strategy and its Implementation, was published in 1995 (in English, 1996) by the Ministry of Finance. At that time, Finland was struggling to find its way out of 
the deep economic depression of the early 1990s. The second strategy is called Quality of Life, Knowledge and Competitiveness: Premises and Objectives for the Strategic Development of the Finnish Information Society and it was published by the Finnish Innovation Fund, Sitra, in 1998. Sitra operates under the supervision of the Finnish Parliament and it agreed with the Ministry of Finance on updating the 1995 strategy. The third national information society strategy, A Renewing, Human-centric and Competitive Finland: The National Knowledge Society Strategy 2007-2015, came out in September 2006. The strategy was published by the Prime Minister's Office, and was designed to promote the previous government's information society programme. The newest strategy for information society development was published in November 2010. This strategy, Productive and Inventive Finland: Digital Agenda for 2011-2020, was compiled under the guidance of Ubiquitous Information Society Advisory Board led by the Minister of Communications.

The information society strategies can be seen as documentations of ongoing political debates and expressions of common interest intended to steer society into a chosen direction. The information society strategies are said to be elitist as only a few influential people are involved in their creation processes (Roivas, 2009, 210). Yet the strategies are also expected to receive approval from a wider audience, who are then expected to act in favour of the goals set in the strategies. This implies that the strategy documents should not be considered only as containers of messages that are detached from their authors and readers. Rather, the strategy papers, like many other material 'agencies', are co-constitutive of mobilities along with human actors. This kind of 'post-human' approach, inspired by 
Bruno Latour, is also strongly present in mobile methodology (Büscher and Urry, 2009, 100).

This study contributes to the mobility paradigm by showing how mobilities are politically promoted and disregarded. In many previous mobilities studies, the researcher's close relationship with the movement under investigation has been stressed. In practice, this has meant ethnographic studies where researchers participate in the explored social and organizational changes and/or in the design of technologies of mobilities (Büscher and Urry, 2009, 111-112). The exploration of written documents, such as strategies and other policy papers, does not allow such an intimate relationship with the 'moves', but it may help us to understand how various prerequisites for corporeal and new digital mobilities, like telecommunication and road infrastructures, are prioritized and implemented on a societal level.

The four information society strategy documents (143 pages in total) will be analysed by means of theory-directed content analysis. As many methodological books have documented (Krippendorf, 2004; Neuendorf, 2002), content analysis has been widely used in different scientific fields, perhaps most notably in communication and media research. The method has multiple variants for qualitative and quantitative purposes, and they vary from completely data-driven (alternatively called conventional analysis) to theory-directed approaches, where data are coded from prior categories derived from a theory (Hsieh and Shannon, 2005). 
The goal of directed content analysis is to legitimize or extend conceptually a theoretical framework (Hsieh and Shannon, 2005, 1281). John Urry’s mobility typology serves as a theoretical framework in this study. In this mode of content analysis, theoretical concepts are not taken for granted and the possibility to revise concepts is reserved. This is an important aspect especially when one is operating with a theoretical framework whose conceptual foundations are not completely established or rigorously tested by empirical means.

\section{ANALYSIS}

The analysis was started by becoming familiar with the official English translations of the four information society strategies. First, all references to five types of mobilities were indentified from each strategy. As a basic rule only such references which clearly indicated the significance of movement were marked, and statements with a reference to a certain technology or means of mobility without a clear relationship to movement were dismissed. For example, the need for building new broadband infrastructure is mentioned several times in the strategies, but was taken into account in the analysis only if a reference to a higher capacity of data transfer, possibility of reducing commuting and increasing teleworking or similar was provided. Second, some specifying principles were applied to guarantee the systematic identification of mobilities. Corporeal modes of movement were relatively easy to detect from the text material. The movement of objects was understood, as Urry (2007, 47) suggests, only as a physical movement of objects. References to immaterial objects and services were then coded as virtual movement as they typically take place through the Internet and are less dependent on industrial time structures. When it comes to imaginative 
movement, only explicit references to print media, television and other possible forms of offline visual media were recorded. In contrast, Internet-based movement was systematically coded as virtual mobility (e.g. online banking, teleconferencing and IPTV-

related statements). Regarding the last category, such formulations that included an idea of person-to-person interaction were coded as communicative mobility. Third, specific attention was paid to how the interdependence and intermingling of mobilities were dealt with in the strategies. In the course of analysis the differences in the fineness of expression and the length of paper became apparent. Whereas the first strategy is relatively short, the following documents reflect more carefully the historical developments and make more efforts to justify the chosen strategic guidelines and actions. Consequently, it became evident that the quantification of mobility statements would have caused a biased picture of the appearance of mobility types in the four strategies.

\section{RESULTS}

This section presents the main results of the study by analysing how different modes of mobility are addressed in the four strategy documents. Table 1 summarizes the results in a relatively simple manner by presenting which mobility types were identified from the documents under investigation.

Table 1 


\section{The 1995 Strategy}

Finland's first information society strategy focuses on the development of a networked economy. The strategy work was said to benefit from the introduction of the information highway concept in the United States and the publication of the Bangemann report in Europe in 1994 (Europe and the Global Information Society..., 1994). The strategy also anticipates that Finland should take an active role in the European Union's information society policy. The 1995 strategy consists of five actions and 46 recommendations.

In terms of mobility, the focus of the strategy is on the physical movement of objects which is supplemented with virtual modes of mobility. In the 1995 strategy networking technologies are perceived as a central competitive factor in economic production (Ministry of Finance, 1996, 6), whereas the virtual exchange of objects through the Internet is considered as having a growing role to play in the future economy. According to the strategy, business and societal structures are being reformed by 'information networks in which information technology merges with the exchanges of data and communications' (Ministry of Finance, 1996. 6). These statements mirror a search for new ways to revitalize the economy and improve the employment rate in the aftermath of the deep economic recession of the early 1990s.

Virtual movement also emerges from the strategy in connection with public access to information. The strategy suggests measures to 'make national information resources and public documents easily accessible to all citizens through public information networks by specifying a uniform delivery channel’ (Ministry of Finance, 1996, 11). It is also promised 
that a schools system will be connected to information networks and their services will be made available to all schools (Ministry of Finance, 1996, 15). Citizens' skills and opportunities to participate in the information society through programmes carried out by schools and adult education are also underlined (Ministry of Finance, 1996, 18, 21). Along with other public sector-related recommendations presented in the 1995 strategy, these can be regarded as an early indication of the government's efforts to develop the ICT infrastructures of the public sector.

References to the corporeal (or bodily) movement of people are only sporadic in the first national strategy. The promotion of teleworking is addressed (Ministry of Finance, 1996, 23), but without a clear reference to the possibility of reducing the physical mobility of people. The strategy does not refer to such issues as domestic commuting or work-related immigration, which could have major impact on the structures and functionality of an information society. Similar observations can be made regarding communicative and imaginative mobility. Some tools for facilitating inter-personal communication are mentioned in the text, yet their relations to social problems generated by communicative mobility are not discussed. Likewise, imaginative movement is not elaborated in the strategy although the launch of digital radio and television broadcastings are mentioned $(14,23)$. As the strategy was tuned to promote the revitalization of the economy, it may be that these two modes of mobility were, at that time, considered as having more impact on people’s private life than on economic growth (i.e. work and business), and were accordingly given considerably less attention.

\section{The 1998 Strategy}


The second national information society strategy was published in 1998. At that time, people's need was said to be a point of departure for the strategic development, which aims to make Finland a forerunner in the implementation of a humane and sustainable information society (Sitra, 1998, 5). Considering today's searing criticism of the lack of centralized management of information society development (National Audit Office of Finland, 2008; Turkki, 2009), the starting-point of the 1998 strategy is illuminative. The strategy argues (Sitra, 1998, 5) that 'it is not possible to steer the development of the information society in a centralised manner'. The need for 'some centralized measures', however, is admitted (Sitra, 1998, 5).

The 1998 strategy is more explicit than the first one in the way it deals with development challenges related to the corporeal mobility of people. In the 1998 strategy the mobility of people, in terms of both growing urbanization and migration, is seen to influence information society development (Sitra, 1998, 6). Also, opportunities provided by new ICTs for the application of more flexible working methods, such as teleworking, with a positive impact on a regional balance in development are much more explicitly articulated (Sitra, 1998, 9). Furthermore, people’s opportunities to remain in and move to remote areas need to be supported by new infrastructure for teleworking and entrepreneurship (Sitra, 1998, 15).

Like its predecessor, the second strategy couples the physical and virtual movements of objects. It also serves as an example of how different modes of mobility are intermingled in the strategies. The 1998 strategy aims to advance the effective and extensive usage of ICTs in society and to promote networking and logistics between enterprises and SMEs in 
particular. Furthermore, the strategy suggests that networking throughout the value chains should be fostered by electronic trade and logistics systems. The development of electronic trade and transactions are also considered important with reference to more flexible access to these services temporally and spatially (Sitra, 1998, 12, 17). It is also anticipated that an increasing share of products and services in different branches will be produced, transmitted, and consumed in an electronic form (Sitra, 1998, 6), which is a clear sign of the growing importance of virtual mobilities for the economy. What is worth noting is that virtual mobility is barely discussed in relation to private life. In this respect, the 1998 strategy follows the previous one by presenting the information society primarily as an economy-driven programme.

People's needs are discussed more in relation to communicative mobilities. For the first time, ICTs are associated with better opportunities for individuals, families and communities to cooperate and interact, regardless of the distance between them (Sitra, 1998, 9). Additionally, personal mobilities are discussed with regard to a proposed project which should develop a set of personal navigation services that 'support all forms of mobility’. The need for combining services related to traffic and transportation, such as maps, addresses, routes, prices and timetables, is also reported (Sitra, 1998, 17). This is also an indication of the need to blend various modes of mobilities in efforts to respond to the new challenges of information-based societies. Neither in the economy nor in private life is the information society developed by focusing on single mobilities.

As in the 1995 strategy, imaginative mobilities are not directly discussed in the 1998 strategy. The strategy takes into account the need to develop cultural provision and increase international interaction (Sitra, 1998, 8) and to covert cultural contents and heritage into an 
accessible and commercially feasible form (rights to work) (Sitra, 1998, 12-13). This is done, however, without any reference to the mobility of cultural images or the like.

\section{The 2006 Strategy}

The vision of Finland's third information society strategy was 'Good life in the information society’ (Prime Minister’s Office, 2006, 9). In the 2006 strategy the focus is said to be shifted from the utilization of ICT to one that generates knowledge-based growth. In this connection the strategy is clearly in line with the Lisbon agreement, which aimed to develop economic growth and quality of life hand in hand to make the EU the most competitive and dynamic knowledge-driven economy.

In the 2006 strategy the corporeal mobility of people is given much more emphasis than in earlier strategies. The development of intelligent services to improve traffic safety and improvements in the productivity and efficiency of transport infrastructure (e.g. real-time driving and weather information) (Prime Minister’s Office, 2006, 21) are mentioned. The public transportation of people is also discussed in relation to the promotion of mobile working by offering wireless broadband connections in various modes of transport, at terminals and at stops (Prime Minister's Office, 2006, 25). This also serves as an example of mixing corporeal mobility with the mediums of virtual movement to solve problems related to changes in working life.

As in the earlier strategies, the mobility of material and virtual objects intersects in the 2006 strategy in multiple ways. ICT is considered to contribute to the development of completely new production models and services. For example, it is stated that electronic and physical 
services, and combinations of them, will be produced and tendered regionally, nationally and internationally (e.g. a remote x-ray diagnosis from Asia) (Prime Minister’s Office, 2006, 11). Compared with prior strategic guidelines, this strategy is also more conscious of the environmental impacts of physical movement of objects (and people). It aims to create opportunities to implement measures and satisfy needs of people without physical movement that stresses the environment and adds to energy consumption. In this respect, such concrete examples as teleworking, videoconferencing and electronic self-services are cited (Prime Minister’s Office, 2006, 13).

Virtual mobilities are also presented elsewhere in the strategy. First, the strategy refers to virtual movement when the promotion of mobile work is discussed. Faster mobile data services, new requirements for organization of work and time use as well as the seamless usability of mobile terminals in different places (Prime Minister’s Office, 2006, 7, 12, 26) are considered important to facilitate the virtual mediums of work. Second, the security of movement in virtual environments is discussed. The strategy aspires to enhance electronic identification solutions that enable movement between different information networks and contribute to the flexible use of various e-services (Prime Minister's Office, 2006, 26). It also warns about the vulnerability of e-society by referring to cybercrimes (Prime Minister’s Office, 2006, 12).

It is a special characteristic of the 2006 strategy that it provides clearer references to imaginative movement. It not only mentions the take-up of digital television and the emergence of IPTV (Prime Minister’s Office, 2006, 26), but it talks about the international benchmarking of ideas which is needed to make successful reforms and innovation (Prime 
Minister’s Office, 2006. 12, 23). The strategy also considers it important to set up a cooperation forum for e-service development and reforms. Such a forum could work as a place for exchanging experiences among participants (Prime Minister’s Office, 2006, 19). Moreover, the strategy argues that Finland has an opportunity not only to develop new services but also to export them worldwide (Prime Minister's Office, 2006, 10). 'The mobility of ideas' is written into this statement, yet not explicitly articulated. The strategy also aims to promote tolerance and interaction between cultures (Prime Minister's Office, 2006, 16) which may take place through the movement of images (in media), although it is not clearly expressed. Lastly, and unexpectedly, the 2006 strategy pays virtually no attention to communicative mobilities. Person-to-person communications are not mentioned in the strategy that is geared to enhance productivity and the international competence of the economy.

\section{The 2010 Strategy}

The 2010 information society strategy has not yet received much public attention in Finland. This novel strategy argues that it reinforces the role of citizens and sustainable development compared with earlier strategies. The 2010 strategy is supposed to be in line with national innovation strategy and the European Union’s digital strategy (Ministry of Transport and Communications, 2010, 8).

The 2010 strategy is more descriptive of challenges and solutions related to corporal movement of people than its predecessors. From the perspective of sustainable development, the strategy states that with the help of ICT 'more can be achieved with less 
material, less transport and less travel' (Ministry of Transport and Communications, 2010, 21). This is followed by an action proposal to emphasize operational and energy efficiency in building constructions and in urban and regional planning to reduce the need for mobility (Ministry of Transport and Communications, 2010, 22). The strategy also suggests that smart technology is steering transport, as well as many other things and processes in society, in an ecological and sustainable direction (Ministry of Transport and Communications, 2010, 11). In addition, the strategy states that as people’s lifestyles are increasingly mobile online services must be developed to serve them in different places (Ministry of Transport and Communications, 2010, 34).

The shift from the industrial society towards service-based economy is reflected in the 2010 strategy by dealing with the physical movement of objects and virtual movement of services side by side. Actually, the focus seems to be shifted from the exchange of material goods towards the production of electronic products and services. Finland is said to emphasize the importance of mobility and e-commerce in products, services and contents 'which requires high data transfer capacity' (Ministry of Transport and Communications, 2010, 26). The strategy also suggests that people should be given the opportunity to pool their everyday transaction needs (e.g. tax and insurance) into one appropriate e-service environment. A flaw is said to be the unfairly high taxation of electronic learning materials compared with printed materials (Ministry of Transport and Communications, 2010, 3537).

The potential of virtual mobility is described more vividly than before, regarding other issues as well. Social media are described as an integral part of interaction and 
communication. They are seen as a way to provide background material for decisionmaking in public administration in readily available and comparable format (Ministry of Transport and Communications, 2010, 11). Social networking is said to 'contribute to strengthening the dialogue between the public and private sector and civil society' (Ministry of Transport and Communications, 2010, 37). Furthermore, people’s own responsibility for the distribution of their personal information is addressed with a reference to digital security and privacy protection. Online billing is also seen as providing a basis for automated and real-time book-keeping, taxing, financing and financial management processes (Ministry of Transport and Communications, 2010, 10, 13).

In the 2010 strategy the communicative mobilities return to a policy agenda. This may well relate to the recent successful application of social media in various contexts, such as election campaigns and natural hazards. It is assumed that with new technologies 'people are acting together and participating in the social fabric new ways' (Ministry of Transport and Communications, 2010. 8). The report also refers to person-to-person communication by suggesting that peer-to-peer learning models would be 'one useful ICT learning avenue for older people and others with special needs' (17). The strategy also reminds us that older people should know how to use the Internet and ICT services to keep in touch with friends and family (Ministry of Transport and Communications, 2010, 17).

\section{CONCLUSION AND DISCUSSION}


The aim of this article was to explore how Finland has taken into account various challenges related to new forms of mobility in its national information society strategies over the last 15 years. The four strategies, which were analysed through a conceptual typology provided by the mobilities paradigm, revealed both augmenting trends and certain discontinuities in how Finland has addressed mobility challenges. One developing trend was that the production of electronic services and products, as well as their dissemination through network infrastructure, gained more and more emphasis over time, whereas the production and transport of material goods were addressed less and less. The other trend was that people's needs for new (mobile) technologies and sustainability, which can be met by reducing corporeal mobility, attracted increasing attention toward the end of the studied period.

The discontinuities related to how strategies dealt with communicative mobility and imaginative movement. Person-to-person communication was first genuinely discussed in the 1998 strategy, but it was then forgotten. In the 2010 strategy communicative mobility was taken up again when the role of social media and the changing patterns of interaction were highlighted. On this basis it would be tempting to argue that if the government wants genuinely to promote a humane and need-driven information society, as proposed in various strategies, it is of great importance to focus more on personal communication mobilities, whose significance for people’s daily social relations and well-being is evident. The other inconsistency in terms of dealing with mobilities relates to forms of imaginative mobility, which were addressed only in the 2006 strategy. On the one hand, this is likely to stem from the vagueness of the concept, which is easily associated only with the 'old' forms of media. On the other hand, imaginative movement effected by such media as TV 
and radio typically takes place at the personal level, which is perhaps a reason why imaginative mobility is only occasionally discussed in the national strategy documents. It follows from this that the study was able to identify only such exchanges of image and ideas that related to national benchmarking practices. The imaginative movement of ordinary citizens was not discussed by any of the studied strategy papers. These findings also raise the question of whether the various modes of mobility presented in Urry's (2007, 47) typology operate differently in micro and macro level analyses. The study hints that whereas corporeal, object, and virtual mobility can take place both at micro and macro levels, communicative and imaginative mobility refer more strongly to the movement at the micro level.

The interdependence and intermingling of mobilities is a pivotal aspect of the entire mobility paradigm (e.g. Larsen, Urry and Axhausen, 2006, 47; Urry, 2007, 26-31). This study showed the necessity to develop various mobilities hand in hand in order to overcome the most severe social problems recognized in Finland's information society strategies. Corporeal movement of people and physical movement of objects have to be developed in conjunction with the immaterial modes of mobility (virtual, communicative and imaginative) in order to promote socially and environmentally sustainable development. Whether the presented guidelines and actions have been successful or not remains outside the focus of this study.

In addition to empirical findings, the study produced some methodological results. The study pointed out that mobility research can be feasibly carried out by analysing the contents of policy documents, yet this approach does not allow a researcher to study 
movement by 'following the people' or 'walking with people' as successfully done in other research settings (Büscher and Urry, 2009, 104). The article also proved that the analysis of policy documents, such as strategies, makes us understand how certain modes of mobility are systematically promoted whereas others are overlooked. Accordingly, more research on societal structures produced by non-human 'agents' that are co-constitutive of movements performed by individuals, communities, nations and cultures is required.

The study also included some constraints. As the investigations focused on the national strategies of a single country, the empirical results of the study are not widely applicable. Despite this, the study also produced many theoretical and methodological insights which will be of interest to mobility scholars in general. On the other hand, the study was based on a relatively small number of strategy papers, which does not do justice to the large number of related strategies (EU level, regional and local level information society strategies, innovation strategies, etc.). Finland's national strategies, however, are to a large extent premised on the EU strategies. The four strategies also contained several thematic continuities from one strategy to another (such as ICT, knowledge and lifelong education as sources of economic growth, the international attractiveness of the Finnish model, Finland's pioneering role in various fields of technology, and so on), which provided a natural basis for the investigations. Regardless of all these limitations, the strategies formed a clearly demarcated but rather versatile basis for analysis.

The results of the study imply that a long-desired genuinely mobile information society has not yet arrived in Finland, at least if the recognition of various mobility types in the national strategy papers is considered as an indicator. The article showed that many new 
modes of mobility are already recognized and addressed in the information society strategies, but the value of others is not yet fully comprehended. Enhancing the mobility of innovative ideas, and other variants of imaginative mobility, in a more systematic manner in the strategies could contribute to a more thorough embedding of new ICT in people's daily life and to more successful combinations of physical and virtual modes of mobility with desirable impacts on the sustainable development of the information society.

Lastly, as regards certain personal mobilities, especially communicative and imaginative, it appears that the national information society strategies do not fully take into account the human and social aspects of the information society. The latest information society strategy takes a step in the right direction, yet it also includes echoes of the technological determinism and market-driven ideology that have characterized the previous strategies (Roivas, 2009, 214). The development of a truly mobile and socially sustainable information society requires a closer dialogue between the social needs of people and the economic needs of society (cf. Serveas, 2003).

\section{ACKNOWLEDGEMENT}

This study is part of a postdoctoral research project funded by the Academy of Finland.

\section{ENDNOTE}


${ }^{1}$ Each strategy was prepared in various stages and included representatives from the different sectors of society (owing to space limitations exact member combinations cannot be presented here). It is, however, characteristic of the boards/steering groups responsible for putting together the final version of the strategy that their members represent various ministries, business and media sectors, government research and development bodies, and employers' organizations. Civil society actors have been poorly, if at all, represented in the decisive phases of framing the strategies. 


\section{REFERENCES}

Banister, D. (2008) The Sustainable Mobility Paradigm, Transport Policy 15(2), pp. 73-80.

Banister, D., Stead, D., Steen, P., Åkerman, J., Dreborg, K., Nijkamp, P. and SchleicherTappese, R. (2000) European Transport Policy and Sustainable Mobility (London: E \& FN Spond).

Beck, U. (2006) Cosmopolitan vision (Cambridge: Polity).

Benner, M. (2003) The Scandinavian Challenge: The Future of Advanced Welfare States in the Knowledge Economy, Acta Sociologica 46(2), pp. 132-149.

Blossfeld, H-P., Buchholz, S. and Hofäcker, D. (2009) Life course inequalities in the globalisation process, in T. Ohnmacht, H. Maksim and M.M. Bergman (Eds.) Mobility and Inequality, pp. 51-74 (Farnham, Surrey: Ashgate).

Büscher, M. and Urry, J. (2009) Mobile Methods and the Empirical, European Journal of Social Theory, 12(1), pp. 99-116.

Büscher, M., Urry, J. and Witchger, K. (Eds.) (2010) Mobile Methods (Abingdon, Oxon: Routledge).

Castells, M. (2000) The Rise of the Network Society. The Information Age: Economy, Society and Culture, Volume I, $2^{\text {nd }}$ ed. (Cambridge, MA: Blackwell).

Castells, M. and Himanen, P. (2002) The Information Society and the Welfare State: The Finnish Model (Oxford: Oxford University Press). 
Cresswell, T. (2010) Towards a Politics of Mobility, Environment and Planning D: Society and Space 28(1), pp. 17-31.

Economist Intelligence Unit (2010) ‘Digital Economy Rankings 2010’ http://www935.ibm.com/services/us/gbs/bus/pdf/eiu_digital-economy-rankings-2010_final_web.pdf (accessed 16/03/2011).

'Europe and the Global Information Society: Bangemann report recommendations to the European Council’ (1994) http://www.epractice.eu/files/media/media_694.pdf (accessed 20/04/2011)

Hsieh, H.-F. and Shannon, S. E. (2005) Three Approaches to Qualitative Content Analysis, Qualitative Health Research 15(9), pp. 1277-1288.

Inkinen, T. (2008) Gender and the social usage of mobile technologies: from information society policies to everyday practices, in T. P. Uteng and T. Cresswell (Eds.) Gendered Mobilities, pp. 213-228 (Aldershot: Ashgate).

ITU (2008) 'Measuring the Information Society. The ICT Development Index' http://www.itu.int/ITU-D/ict/publications/idi/2009/material/IDI2009_w5.pdf (accessed 16/03/2011).

ITU (2009) 'Measuring the Information Society 2010’ http://www.itu.int/ITUD/ict/publications/idi/2010/Material/MIS_2010_without_annex_4-e.pdf (accessed 16/03/2011). 
Kaufmann, V. and Montulet, B. (2008) Between social and spatial mobilities: the issue of social fluidity, in W. Canzler, V. Kaufmann and S. Kesselring, (Eds.) Tracing Mobilities: Towards a Cosmopolitan Perspective, pp. 37-55 (Aldershot: Ashgate).

Klee, K. and Bensk, J. (1999) The Future is Finnish, Newsweek, 24, May 1999.

Kopomaa, T. (2000) The City in Your Pocket: Birth of the Mobile Information Society (Helsinki: Gaudeamus).

Krippendorff, K. (2004) Content Analysis: An Introduction to its Methodology. 2 ed. (London: Sage).

Larsen, J., Urry, J. and Axhausen, K. (2006) Mobilities, Networks, Geographies (Aldershot: Ashgate).

Ministry of Finance (1996) Finland's Way to the Information Society: The National Strategy and Its Implementations (Ministry of Finance: Helsinki).

Ministry of Transport and Communications (2010) 'Productive and inventive Finland:

Digital Agenda for 2011-2020’

http://www.arjentietoyhteiskunta.fi/files/322/Digitaalinen_agenda_eng.pdf (accessed 10/03/ 2011).

National Audit Office of Finland (2008) 'Alueellisten tietoyhteiskuntahankkeiden toteutus’ [Implementation of Regional Information Society Projects] http://www.vtv.fi/files/130/1582008_Alueellisten_tietoyhteiskuntahankkeiden_toteutus_N ETTI.pdf (accessed 23/03/2011). 
Neuendorf, K. A. (2002) The Content Analysis Guidebook (London: Sage).

Ohnmacht, T., Maksim, H. and Bergman, M. M. (2009) Mobilities \& inequalities: making connections, in T. Ohnmacht, H. Maksim and M.M. Bergman (Eds.) Mobility and Inequality, pp. 7-26 (Farnham, Surrey: Ashgate).

Oksman, V. (2006) Young People and Seniors in Finnish 'Mobile Information Society', Journal of Interactive Media in Education 2006(02), pp. 1-21.

Paija, L. (2001) What is Behind the Finnish 'ICT Miracle'?, The Finnish Economy and Society 17(3), pp. 51-54.

Pellegrino, G. (Ed.) (2011) The Politics of Proximity Mobility and Immobility in Practice (Aldershot: Ashgate).

Peters, P. F. (2006) Time, Innovation and Mobilities: Travel in Technological Cultures (London: Routledge).

Prime Minister’s Office (2006) ‘A Renewing, Human-Centric and Competitive Finland: The National Knowledge Society Strategy 2007-2015’

http://vnk.fi/julkaisukansio/2006/tietoyhteiskuntaneuvosto/tietoyhteiskuntastrategia/en.pdf (accessed 14/03/ 2011).

Puro, J.-P. (2002) Finland: a mobile culture, in J. E. Katz and M. Aakhus (Eds.) Perpetual Contact: Mobile Communication, Private Talk, Public Performance, pp. 19-29 (Cambridge: Cambridge University Press). 
Roivas, S. (2009) Tietoyhteiskunnan lupaus: Tieto- ja kommunikaatioteknologioiden sosiaalisesta soveltamisesta [The Promise of Knowledge-based Society- On the social applying of information and communication technologies]. Acta Universitatis Tamperensis 1402 (Tampere: Tampere University Press).

Servaes, J. (2003) The European information society: a wake-up call, in J. Servaes (Ed.) . The European Information Society: A Reality Check, pp 11-32 (Bristol: Intellect Book).

Sheller, M and Urry, J. (Eds.) (2004) Tourism Mobilities: Places to Play, Places in Play (London: Routledge).

Sheller, M. and Urry, J. (Eds.) (2006) Mobile Technologies of the City (New York: Routledge).

Silberman, S. (1999) 'Just say Nokia’ http://www.wired.com/wired/archive/7.09/nokia.html (accessed 21/03/2011).

Sitra (1998) 'Quality of life, knowledge and competitiveness: premises and objectives for strategic development of the Finnish information society’ http://www.sitra.fi/julkaisut/tietoyhteiskunta/sitra211.pdf?download=Lataa+pdf (accessed 14/03/2011).

Taipale, S. (forthcoming) Mobility of Cultures and Knowledge Management in Contemporary Europe, The European Review.

Turkki, T. (2009) ’Nykyaikaa etsimässä. Suomen digitaalinen tulevaisuus’ [In search of modern times. The digital future of Finland] http://www.eva.fi/wpcontent/uploads/files/2573_nykyaikaa_etsimassa.pdf (accessed 16/03/2010). 
Urry, J (2000a) Sociology Beyond Societies: Mobilities for the Twenty-First Century (London: Routledge).

Urry, J. (2000b) Mobile Sociology, British Journal of Sociology 51(1), pp. 85-203.

Urry, J. (2002) Mobility and Proximity, Sociology 36(2), pp. 255-274.

Urry, J. (2003) Social Networks, Travel and Talk, British Journal of Sociology 54(2), pp. $155-75$.

Urry, J. (2007) Mobilities (Cambridge: Polity).

Webster, F. (2002) Theories of the Information Society (London: Routledge).

Wimmer, A. and Glick Schiller, N. (2002). Methodological Nationalism and Beyond:

Nation-State Building, Migration and the Social Sciences, Global Networks 2(4), pp. 301334. 
Table 1. Mobility types identified from Finland's information society strategies between 1995 and 2010

\begin{tabular}{|c|c|c|c|c|}
\hline Mobility typology* & The 1995 Strategy & The 1998 Strategy & The 2006 Strategy & The 2010 Strategy \\
\hline Corporeal & & $X$ & $X$ & $\mathrm{X}$ \\
\hline Object & $\mathrm{X}$ & $X$ & $\mathrm{X}$ & $X$ \\
\hline Imaginative & & & $\mathrm{X}$ & \\
\hline Virtual & $\mathrm{X}$ & $X$ & $X$ & $X$ \\
\hline Communicative & & $\mathrm{X}$ & & $\mathrm{X}$ \\
\hline
\end{tabular}

*Presented as it appears in Urry 2007, 47

Note: Letter $\mathrm{X}$ indicates that the mobility type was identified in the document 